\title{
Diagnostic features of prematurely fused cranial sutures on plain skull X-rays
}

\author{
Tilmann Schweitzer ${ }^{1}$
}

Received: 10 November 2015 / Accepted: 13 November 2015 /Published online: 20 November 2015

(C) Springer-Verlag Berlin Heidelberg 2015

We appreciate this valuable comment. As we have underlined in our paper and published in earlier articles [1-3], we absolutely agree with the high value of clinical analysis. In fact, we have abandoned radiographic examination in the vast majority of cases that we do not operate on.

On the other hand, plain radiographs do provide additional information such as a deep midline bony groove in sagittal synostosis or perforating vessels of significant size in frontal synostosis, which may well be important to know prior to surgery. This kind of information contributes to the safeness of the surgical procedure, but - at least in Germany-may also be helpful for the surgeon in the rare but serious case of a legal dispute. During follow-up, plain X-rays may provide crucial information on the inner surface of the vault ("copper beaten" skull), at least on progressive multisutural fusion putting the patient at risk of intracranial hypertension and thus helps to adjust intervals and mode of checkups. As we have learned, even in case of significant intracranial hypertension, papilledema is sometimes absent. In addition, some "isolated" monosutural synostosis might turn out to be syndromal, such as a sagittal synostosis in Crouzon syndrome or coronal synostosis in Saethre-Chotzen syndrome, both associated with a high risk of elevated intracranial pressure during childhood and adolescence.

Tilmann Schweitzer

schweitzer_t@ukw.de

1 University of Würzburg, Würzburg, Germany
Above all, our paper is directed against the still widespread use of CT scanning which exposes the young patients to a significantly higher radiation compared with a modern radiograph. We agree with Dr. Constantini that even plain radiographs can and certainly should be further reduced in the diagnostic workup of craniosynostosis. But we want to advise against abandoning this simple auxiliary technique in all cases of simple or allegedly simple monosutural craniosynostosis. Though underrepresented in many clinical algorithms, we tried to call attention for plain skull radiographs and depicted the characteristic features of pathologic suture conditions for further education.

\section{Compliance with ethical standards}

Conflict of interest The author has no conflict of interest.

\section{References}

1. Linz C, Collmann H, Meyer-Marcotty P, Böhm H, Krauss J, Müller-Richter UD, Ernestus RI, Wirbelauer J, Kübler AC, Schweitzer T (2015) Occipital plagiocephaly: unilateral lambdoid synostosis versus positional plagiocephaly. Arch Dis Child 100(2):152-157

2. Linz C, Meyer-Marcotty P, Böhm H, Müller-Richter U, Jager B, Hartmann S, Reichert C, Kochel J, Schweitzer T (2014) 3D stereophotogrammetric analysis of operative effects after broad median craniectomy in premature sagittal craniosynostosis. Childs Nerv Syst 30(2):313-318

3. Schweitzer T, Böhm H, Meyer-Marcotty P, Collmann H, Ernestus RI, Krauß J (2012) Avoiding CT scans in children with single-suture craniosynostosis. Childs Nerv Syst 28(7):1077-1082 